\title{
Una mirada a las actividades del Departamento de Bellas de Artes
}

\author{
Liliana Dosamantes Monteverde, Francisco Andrés Soqui \\ Ruiz y Luis Alfredo Díaz de León Huez \\ Alumnos de la Licenciatura en Música
}

Los 75 años de nuestra universidad enmarcaron el vigésimo aniversario de las licenciaturas del Departamento de Bellas Artes. Ambos eventos generaron múltiples actividades artísticas y culturales. En el primero se llevó a cabo una velada con mucha música donde destacaron las presentaciones de La Banda de Música de la Universidad de Sonora, bajo la conducción del maestro Horacio Lagarda y Jenny and the Mexicats; mientras que, en el segundo, recitales, charlas, festivales, coloquios, concursos y presentaciones de danza y teatro hicieron su aparición.

Para los estudiantes de artes es de suma importancia tener espacios donde se ponga en práctica lo que se aprende en las aulas y, al mismo tiempo, ofrecer al público en general un espacio para el disfrute de lo que aquí se hace y se vive. Para ello hubo varios programas como Martes Danza, conciertos conCiencia, Jueves Teatro y Viernes de Concierto, en donde pudimos disfrutar una muestra del trabajo de alumnos/as activos, así como de egresados y maestros.

En septiembre, la tragedia llegó a México. Los terremotos del 7 y 19 de septiembre dejaron a su paso estragos en estados del centro y sur del país. Muertes, derrumbe de inmuebles e incontables daños estructurales en las ciudades afectadas dejaron a miles de mexicanos en situaciones deplorables. Ante las circunstancias, todo México se solidarizó con los afectados y el Departamento de Bellas Artes se sumó a la causa. Además de las colectas de víveres y donativos se ofrecieron programas para la recaudación de donativos. Algunos de ellos fueron: Un canto para el sur, un concierto colaborativo de música mexicana que se llevó a cabo en el Teatro Emiliana de Zubeldía; Bailando por ayudar, un programa de clases de baile que se impartieron en el centro de las artes; Las vampiras vegetarianas, función de teatro realizada en el Quiosco del arte, entre otros. Como cada año, llegó la víspera del 2 de noviembre y nuestra universidad se sumó al festejo de nuestros difuntos al estilo mexicano. Como era de esperarse, se realizó una vez más la tradicional procesión del día de muertos en la que participaron alumnos/as y maestros/as de todo el Departamento. Catrinas, catrines, músicos y bailarines llevaron la celebración a distintos espacios de la universidad y calles aledañas dispuestas como las

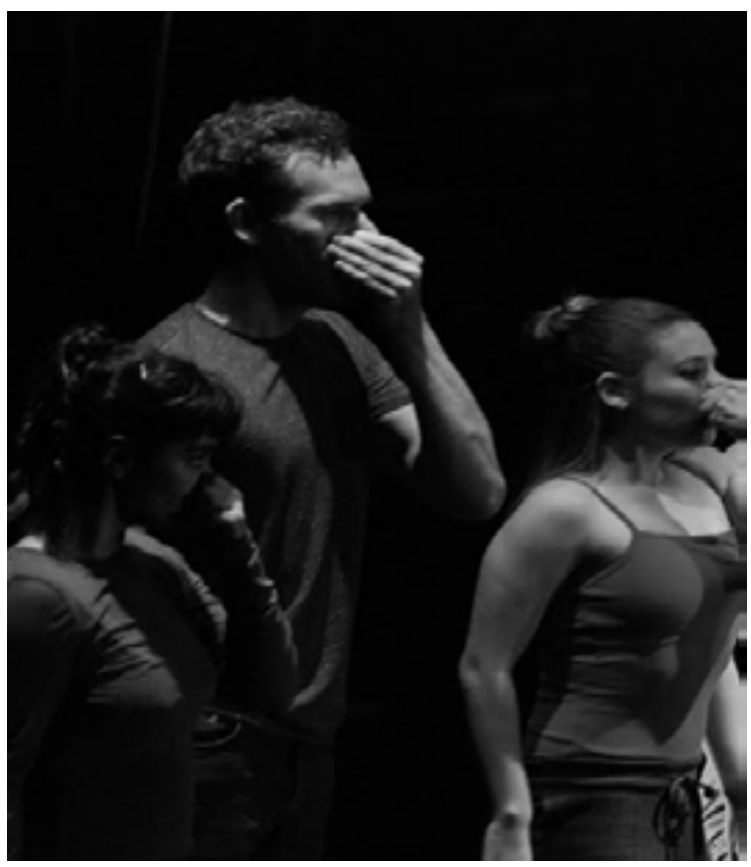

Ana Isabel Campillo 
siete estaciones, en las que pudimos disfrutar de cada uno de los números alusivos al festejo. Otra tradición universitaria es el Festival Catrina, organizado por la Licenciatura en Artes Plásticas, que es muy esperado por todo el estudiantado; ya que representa una colaboración de todas las Licenciaturas en artes. En este evento pudimos disfrutar de muestras de música, danza, teatro y artes plásticas, además de los concursos de altares y de catrinas.

Hubo muchísimos eventos especiales realizados por parte o con participación de nuestra alma mater. Entre ellos: El XIV Festival internacional de guitarra de Sonora, Festival de Otoño, Concierto de Jazz por parte de la Banda de Música de la Universidad de Sonora de Horacio Lagarda, Concierto "De viejos amores", Concierto de Arody García, "Cerrando un ciclo.. del son a la vanguardia”, El II Concurso de Canto Lírico de la Universidad de Sonora, "Los sones como son", El Coloquio de danza contemporánea, Variopinta Festival cultural LGBT+ y el programa Músicos Trabajando. Este último patrocinado por el ISC y orquestado por Oscar Mayoral, en el cual participaron tanto maestros como egresados. Un rico programa con música que va desde el barroco, el cual estuvo a cargo de la Maestra en música Antigua Mariana Mevans, hasta música contemporánea para instrumentos tales como guitarra, flauta, voz y piano, entre otros.

El año está por terminar y podemos darnos cuenta de que este fue un semestre colmado de actividades artísticas en todas sus disciplinas. En ellas, se muestra el trabajo y el esfuerzo de la comunidad universitaria de las artes por difundir su trabajo, no sólo en la universidad; sino también en nuestro estado.

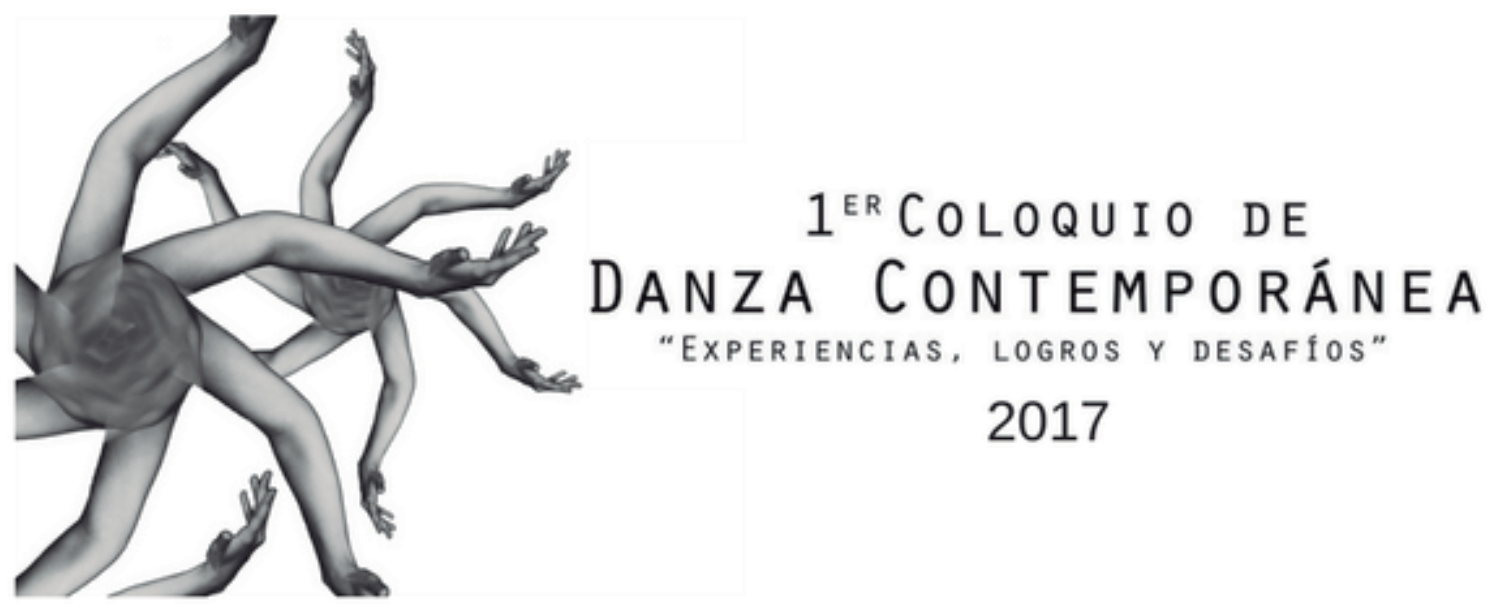

Ier Coloquio de Danza Contemporánea 